\title{
Nutritional Implications of Patients with Dysautonomia and Hypermobility Syndromes
}

\author{
Toan Do ${ }^{1}$ (1) Sarah Diamond ${ }^{2} \cdot$ Caitlin Green $^{3} \cdot$ Malissa Warren $^{4}$ \\ Accepted: 17 August 2021 / Published online: 12 September 2021 \\ (c) The Author(s), under exclusive licence to Springer Science+Business Media, LLC, part of Springer Nature 2021
}

\begin{abstract}
Purpose of Review Dysautonomia and hypermobility syndrome are two distinct but often overlapping clinical conditions that are recognized for their complex multiorgan system afflictions. The purpose of this review is to investigate dietary strategies to reduce symptoms and augment quality of life in this growing patient population.

Recent Findings There is increasing evidence supporting dietary modifications to include food rich in probiotics and prebiotics, along with fiber supplements to reduce gastrointestinal symptoms. Adequate salt and fluid intake may reduce orthostatic hypotension symptoms. Dietary supplements may help with osteoarticular, musculoskeletal, and fatigue symptoms.

Summary Individualized dietstrategies and supplements can reduce the multiorgan system symptoms observedin dysautonomia and hypermobility syndrome.
\end{abstract}

Keywords Dysautonomia $\cdot$ Hypermobility Syndrome $\cdot$ Nutrition $\cdot$ Orthostatic $\cdot$ POTS $\cdot$ Ehlers-Danlos

\section{Introduction}

Hypermobility syndromes are connective tissues disorders that often present with autonomic dysfunction [1-3]. Autonomic dysfunction, also called dysautonomia, is any change

This article is part of the Topical Collection on Gastroenterology, Critical Care, and Lifestyle Medicine

Toan Do

doto@ohsu.edu

$\triangle$ Malissa Warren

warrenma@ohsu.edu

Sarah Diamond

diamonsa@ohsu.edu

Caitlin Green

Caitlin.homberger@gmail.com

1 Internal Medicine, Oregon Health \& Science University, Portland, OR, USA

2 Division of Gastroenterology \& Hepatology, Oregon Health \& Science University, Portland, OR, USA

3 Division of Gastroenterology \& Hepatology, Medical University of South Carolina, Charleston, SC, USA

4 Department of Surgery, Oregon Health \& Science University, Portland, OR, USA in the autonomic nervous system (ANS) that adversely affects health $[4,5]$. Autonomic dysfunction can impact major organ systems including nervous, circulatory, respiratory, endocrine, and digestive and excretory systems [6-8]. This patient population is increasingly recognized for their complex gastrointestinal symptoms. Further understanding of the nutritional implications in this subgroup of patients will be integral in providing optimal multidisciplinary care and improving quality of life, while reducing morbidity and healthcare utilization.

\section{Classification of Dysautonomia and Hypermobility Syndromes}

Dysautonomia is associated with several diseases that can be categorized into primary versus secondary. Primary conditions of dysautonomia include neurogenic syncope, postural orthostatic tachycardia syndrome (POTS), familial dysautonomia (FD), and multiple system atrophy. Of the four major conditions of primary dysautonomia, postural orthostatic tachycardia syndrome (POTS) appears to have the most impact on the gastrointestinal system and nutritional status [9]. Several diseases are associated with secondary dysautonomia including gastrointestinal conditions 
such as inflammatory bowel disease, celiac, and eosinophilic esophagitis; neurological and autoimmune conditions such as Parkinson's, muscular sclerosis, and lupus; and infections such as HIV, Lyme disease, and COVID-19 [2, 5, 10-16]. Further studies are required to elucidate the pathophysiology and clinical impact of dysautonomia in these conditions.

Hypermobility syndromes are a complex and multisystemic spectrum of conditions. Hypermobility can be asymptomatic or can present with joint manifestations (arthritis, arthralgia) and soft tissue injuries. When associated with clinical symptoms, the condition is termed joint hypermobility syndrome (JHS) [17]. The symptoms of JHS are considered benign and distinguished from other potentially life-threatening connective tissue disorders such as Marfan syndrome and Ehlers-Danlos syndrome (EDS) [18]. EDS is a group of heritable disorders, characterized by non-inflammatory conditions of connective tissue that present with musculoskeletal symptoms, hyperflexible joints, and hyperelastic skin [19]. Recent literature suggests that clinically, JHS is similar to a subgroup called Ehlers-Danlos syndrome hypermobility type (EDS-HT) [2]. Extra-articular manifestations of JHS include skin laxity and fragility, ocular ptosis, varicose veins, Raynaud's phenomenon, developmental motor delay, fibromyalgia, and low bone density $[20,21]$.

\section{Epidemiology and Demographics}

Postural orthostatic tachycardia syndrome (POTS), recognized in 1993 by Ron Schndorf and Phillip Low, is among the most common causes of chronic orthostatic intolerance [9, 22]. POTS is diagnosed when positional change from supine to upright posture results in a sustained heart rate increase of $>/ 30$ beats per minute (or $>/ 40$ in patients $<19$ years of age) with symptoms of orthostatic intolerance (dizziness, lightheadedness, blurry vision, tremulousness, weakness) [23-25]. The symptoms need to be chronic ( $>/ 3$ months) and the observed tachycardia should be in the absence of orthostatic hypotension ( $>/ 20 / 10 \mathrm{~mm} \mathrm{Hg}$ ). POTS afflicts approximately 500,000 Americans, most of whom are of white race (93\%) and female sex of child bearing age (94\%) $[26,27]$. The condition can result in significant financial cost to the individual. In a study of 4468 individuals ( $>$ /18 years old) diagnosed with POTS, about $75 \%$ reported inability to work for at least a week and $67 \%$ had to modify their employment responsibilities due to symptoms [28].

The prevalence of joint hypermobility syndrome (JHS) varies in literature due to differing diagnostic criteria. It is generally recognized that the condition is more prevalent in those of Asian or African descent, children and adolescents, and in females [29-31]. A study of 655 subjects ( 482 females) US college students estimated that $12.5 \%$ have generalized joint hypermobility [32]. Although the prevalence of JHS differs across races and age, this condition is likely underdiagnosed, and the number of individuals impacted by this condition is expected to be higher. Similar to JHS, Ehlers-Danlos syndrome is considered an underdiagnosed condition. It is estimated that 1 in 5000 individuals have Ehlers-Danlos syndrome (all types) [33].

\section{Overlap of Dysautonomia and Hypermobility Syndromes}

The association between hypermobility conditions and dysautonomia is increasingly demonstrated in literature and recognized clinically. Possible mechanisms to explain dysautonomia in EDS include adreno-receptor hyperresponsiveness, peripheral neuropathy, and molecular defect in blood vessel connective tissues [2, 18, 34]. A study of 48 subjects with JHS (1998 Brighton criteria) demonstrated 78\% (21/27) experienced orthostatic intolerance compared with $10 \%(2 / 21)$ of controls [2]. Subjects with JHS also reported greater increase in systolic blood pressure after cold pressor test $(10 \pm 10 \mathrm{~mm}$ $\mathrm{Hg}$ vs $11 \pm 13 \mathrm{~mm} \mathrm{Hg}$ ) with evidence of $\beta$-adrenergic and $\alpha$-adrenergic hyperresponsiveness compared to controls. Celletti et al. demonstrated in 25 individuals diagnosed with JHS or Ehlers-Danlos syndrome hypermobility type (EDSHT), $48.6 \%$ subjects showed postural orthostatic tachycardia on head-up tilt table test and $31.4 \%$ had symptoms of orthostatic intolerance [35]. At resting state, these JHS/EDS-HT subjects also showed significantly higher baroreflex sensitivity compared to controls. A study of 84 subjects with EDS-HT showed these subjects had lower total peripheral resistance and higher heart rate at head-up tilt (70 degree) tests [36].

There is increasing literature reporting the concurrent diagnoses and overlapping symptoms of POTS and EDSHT. Wallman et. al. reviewed 109 medical records and demonstrated that in subjects with POTS, about $18 \%$ also had EDS compared to $0.02 \%$ in the general population [37]. The odds ratio of EDS in POTS versus non-POTS patients is 4.9. Individuals with POTS and JHS present with symptoms at an earlier age ( 23 years old \pm 13 versus 41 years old \pm 12 ) compared to individuals with POTS without JHS [38]. Beyond dysautonomia, individuals with JHS/EDS-HT have a range of symptoms that overlap with other conditions such as chronic pain syndromes, chronic fatigue syndrome, anxiety disorder, pelvic floor dysfunction, and exocrine gland dysfunction [39].

\section{Gastrointestinal Symptoms in Dysautonomia and Hypermobility Syndromes}

Gastrointestinal (GI) symptoms are highly prevalent in individuals with JHS/EDS-HT and contribute to significant functional debility and adverse nutritional consequences. In 
a pilot study in 2010, Castori et al. found 18/21 (86\%) subjects with JHS/EDS-HT reported GI symptoms that included constipation/diarrhea (33.3\%), abdominal pain/discomfort (61.9\%), gastroesophageal reflux $(57.1 \%)$, and dyspepsia (66.7\%) [40]. The same year, Zarate et al. reported frequent GI symptoms in 21 subjects with JHS/EDS-HT, including dysphasia (14.3\%), gastroesophageal reflux (52.4\%), bloating $(57.1 \%)$, vomiting $(57.1 \%)$, recurrent abdominal pain $85.7 \%$, and constipation/diarrhea (76.2\%) [41]. Zarate et. al. also found abnormal esophageal manometry (33.3\%), abnormal 24-h pH-ambulatory monitoring (33.3\%), delayed gastric emptying (80\%), abnormal small bowel manometry (44.4\%), and abnormal colorectal transit (100\%). Fikree and colleagues reported that subjects with JHS were found to have an odds ratio (OR) 1.66 for heartburn, OR 2.02 for water brash, and OR 1.74 for postprandial fullness compared to non-JHS controls [42]. A positive, linear correction between the severity of JHS and GI symptoms were observed in this population. In a recent retrospective review, Zhou et al. found that $35 \%$ of EDS-HT patients who underwent breath testing had small intestinal bacterial overgrowth (SIBO), of which $92 \%$ were methane positive, while only $35 \%$ were hydrogen positive. Unlike SIBO in the general population, EDS-HT patients with SIBO were more likely to be constipated compared to EDS patients without SIBO (50.00 vs. $26.53 \%, p=0.042$ ) [43].

Dysautonomia further exacerbates GI complications in EDS-HT individuals. The autonomic nervous system controls the "fight or flight" versus "rest and digest" response [44]. An imbalance of this binary state causes individuals with EDS-HT an inability to be in the "rest and digest" state when appropriate. There is increasing literature demonstrating that dysautonomia is a major factor to a spectrum of GI complaints [41-45]. Dysbiosis and dysregulation of gutrelated immune function may be linked to a higher prevalence of food allergies and inflammatory or autoimmune disorders observed in EDS-HT individuals [46, 47].

\section{Nutritional Management}

Identifying and correcting nutritional deficiencies is the cornerstone of nutritional management for patients with dysautonomia and/or JHS/EDS-HT. Although literature on nutritional management of this population is limited, the spectrum of symptoms observed in this population have been demonstrated to be significantly influenced by nutritional status and dietary intake. Primary nutrition recommendations most often include diet modification, nutrition support therapies, and micronutrient supplementation to improve or maintain nutrition status when symptoms have resulted in suboptimal oral intake, altered utilization of nutrients, and significant weight loss [48••]. As with any chronic disorder, a thorough nutrition assessment that includes dietary history, weight history, past medical and surgical history, medication/supplement review, GI function, and a comprehensive nutrition focused physical exam is necessary to determine appropriate nutrition therapies.

There is theorizing in the literature that alternative therapies including modified diets and nutritional supplements may improve symptoms related to dysautonomia and JHS/ EDS-HT; however, given the extrapolative nature and lack of empirical investigation, these nutritional suggestions should be considered low-level recommendations [39]. An individualized plan of nutritional management that includes careful monitoring of symptoms with a multidisciplinary approach that includes gastroenterology, nutrition, psychiatry, and pain management, and neurology is likely to yield the best results $[49 \bullet \bullet]$.

\section{Diet Modifications}

The spectrum of gastrointestinal symptoms experienced by individuals with dysautonomia and JHS/EDS-HT can be ameliorated through various nutritional supplements and avoidance of specific foods (Table 1). These recommended modifications may not have been studied in patients with dysautonomia but are extrapolated from studies in subjects with conditions that have similar symptoms as those with dysautonomia and JHS/EDS-HT.

Diarrhea and constipation are two common GI symptoms of individuals with dysautonomia and HMS/EDS-HT. Soluble fiber supplements not only reduce diarrhea but have also demonstrated long-term protective effects against metabolic disorders, cardiovascular disease, and colon cancer along with promoting bowel regularity $[11,50]$. A low FODMAP (fermentable oligo, di, mono-saccharides, and polyol) diet has been shown to reduce symptoms of diarrhea, bloating, and flatulence in individuals with irritable bowel syndrome (IBS) by $50-80 \%$ [51]. Similarly, a gluten-free diet has been demonstrated to reduce diarrhea and abdominal discomfort in some individuals with IBS [52]. Probiotics such as Lactobacillus GG and Bifidobacterium lactis can also reduce frequency of diarrhea [53]. For individuals who experience constipation, fiber supplementation has been demonstrated to increase stool frequency [54]. It should be noted that the impact of fiber on stool consistency and pain with defecation is marginal.

Optimization of the gut microbiome may promote digestion and reduce GI symptoms in this population. The gut microbiome plays an increasingly recognized role in digestion, gut inflammation, and absorption of nutrients [55, 56]. These beneficial bacteria in the gut assist in the digestion of resistant starches and lipids, synthesis short-chain fatty acid, and absorption of essential fat soluble vitamins (A, 
Table 1 Dietary

recommendations for gastrointestinal, orthostatic hypotension, osteoarticular, musculoskeletal pain, and fatigue in individuals with dysautonomia and hypermobility syndrome

\begin{tabular}{|c|c|}
\hline Symptoms & Recommendations \\
\hline Gastrointestinal & 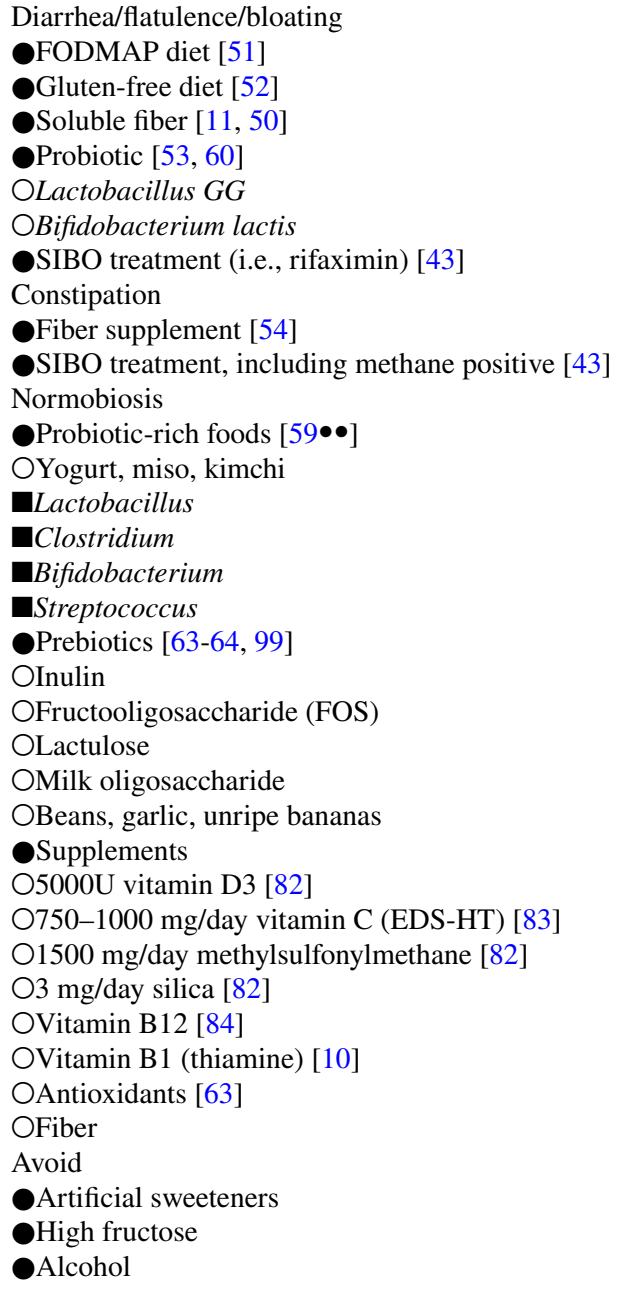 \\
\hline Orthostatic hypotension & $\begin{array}{l}\text { Salt }[75 \bullet \bullet, 76,77] \\
\text { American Journal of Cardiology (2017) } \\
\text { O6-9 g (100-150 mmol) per day } \\
\text { American Society of Hypertension (2013) } \\
\text { O6-10 g NaCl } \\
\text { American Family Physician (2011) } \\
\text { OSalty food and 0.5-1 g tablets } \\
\text { Fluid [75••, 76, 77] } \\
\text { American Society of Hypertension (2013) } \\
\text { O1.5-2L } \\
\text { OEuropean Society of Cardiology (2018) } \\
\text { O2-3L fluids } \\
\text { Size \& Temperature [74] } \\
\text { OSmall, frequent meals } \\
\text { O6 smaller meals > } 3 \text { large } \\
\text { Room temperature }\end{array}$ \\
\hline Osteoarticular & $\begin{array}{l}\text { Joint [89-91] } \\
1500 \mathrm{mg} \text { /day glucosamine } \\
1200 \mathrm{mg} \text { /day chondroitin sulfate } \\
1228 \mathrm{mg} \text { /day manganese ascorbate }\end{array}$ \\
\hline Musculoskeletal pain & $\begin{array}{l}\text { MSK }[92,93] \\
250 \mathrm{mg} / \text { day carnitine } \\
100 \mathrm{mg} / \text { day coenzyme Q10 } \\
\text { Reducing Inflammation [88] } \\
240 \mathrm{mg} \text { /day y-linolenic acid }\end{array}$ \\
\hline
\end{tabular}


Table 1 (continued)

\begin{tabular}{ll}
\hline Symptoms & Recommendations \\
\hline Fatigue & Supplements [92, 96, 98] \\
& OCoenzyme Q10 \\
OMagnesium & ONicotinamide adenine dinucleotide (NADH) \\
OAlpha-lipoic acid
\end{tabular}

$\mathrm{D}$, E, and $\mathrm{K}$ ) and minerals ( $\mathrm{Ca}, \mathrm{Mg}$, and $\mathrm{Fe})[54,57,58]$. To reestablish normobiosis, patients should eat foods high in probiotics (yogurt, miso, kimchi) that contain organisms such as lactobacillus, clostridium, bifidobacterium, and streptococcus [59••, 60, 61]. These organisms have been shown to promote digestion and reduce gut inflammation in conditions such as IBD and celiac disease. Prebiotics, defined as compounds that are metabolized by beneficial gut bacteria, are another source to promote gut health [59••, 62]. Food rich in prebiotics include inulin, fructooligosaccharide (FOS), lactulose, milk oligosaccharide, beans, garlic, and unripe bananas. Supplements of antioxidants and fiber can further support growth of beneficial gut bacteria [63, 64].

Avoidance of certain foods may prevent dysbiosis. Processed foods, including refined carbohydrates, and those high in salt such as cured meats, contribute to dysbiosis [65]. Artificial sweeteners may promote harmful gut organisms like Proteobacteria, and contribute to gut inflammation, glucose intolerance, and breakdown of the GI intestinal barrier that result in a "leaky gut" [66-68]. A dysfunctional GI intestinal barrier that allows "leakage" of material in and out of the body has been linked to several GI symptoms including bloating, cramps, food allergies, gas, and headaches [69••]. A "leaky gut" may be associated with multiple sclerosis, inflammatory bowel disease, depression and other mood disorders, and autoimmune conditions. Similarly, a diet high in fructose and alcohol consumption has been linked to dysbiosis and increased gut permeability [70, 71].

\section{Salt and Fluid Intake}

Various nutritional strategies can be appliedto reduce orthostatic symptoms experienced by individuals with primarydysautonomia or JHS/EDS-HT. Mathias et al. demonstrated that water intake of 2-2.5L/day and salt ingestion $>8 \mathrm{~g}(150 \mathrm{mmol} /$ day $)$ can improve orthostatichypotension [72]. Adequate water intake can reduce changes in blood pressureand heart rate in subjects with severe orthostatic hypotension [73].Subjects who drank $480 \mathrm{~mL}$ of tap water at room temperature within 5 min demonstratedless blood pressure decrease $(22 \pm 10 / 12 \pm 5 \mathrm{~mm} \mathrm{Hg})$ compared to those withoutdrinking water $(43 \pm 36 / 20 \pm 13 \mathrm{~mm} \mathrm{Hg})$ with position change. This is believed to besecondary to a rapid pressor response in individuals with autonomic failure.
Puvi-Rajasingham et al. demonstrated that in subjects with primary chronicautonomic failure, having 6 smaller meals instead of three larger mealsresulted in fewer symptoms of dizziness and lightheadedness with positionalchanges [74].

Increasing salt intake in individuals withorthostatic hypotension has been recommended by the 2017 ACC/ AHA/HRS guidelineand the American Family Physician, although with varying amounts [75••, 76-77].Low (2008) and colleagues studied subjects with neurogenic orthostatichypotension and reported that salt supplementation is essential [78].After checking 24-h urinary sodium, individuals with value $<170 \mathrm{mmol}$ can besupplemented with $1-2 \mathrm{~g}$ of sodium tablets three times a day. Figueroa et al. proposed salty soup and approximately $8 \mathrm{oz}$. serving of fluid over half a day or $2 \mathrm{~g}$ salt tablets three times a day with a minimum of eight 8-oz serving offluid over a day to reduce orthostatic decompensation [79].It should be recognized that there is low-quality evidence that increased saltintake reduces orthostatic intolerance [77].A meta-analysis of 14 studies with 391 subjects demonstrated that increase saltintake resulted in higher systolic blood pressure by 12 $\mathrm{mmHg}$ and fewer reportedsymptoms of orthostatic intolerance. Although long-termempirical investigation is needed in subjects with dysautonomia to assess thefull impact of dietary salt on symptoms, increasing the quantity of salt indiet may reduce the frequency and severity of orthostatic hypotension in this population.

\section{Micronutrients}

Individuals with EDS-HT and dysautonomia areat risk for micronutrient deficiencies, due to limitations in dietary intakeand bacterial overgrowth and may require either oral or parenteralsupplementation. EDS-HT patients are known to have low vitamin D serum levels [80, 81]. It is recommended that EDS-HT individuals take 5000U daily of vitamin D3(cholecalciferol) year-round or at a minimum during non-summer months. Toreduce complications of skin fragility and promote wound healing, individualswith EDS-HT should take 750-1000 mg/day vitamin C and $1500 \mathrm{mg} /$ day of methylsulfonylmethane (MSM)plus silica $3 \mathrm{mg} /$ day [82]. Vitamin C, also called ascorbic acid, is a cofactor in collagen synthesis and is rapidly consumed in the wound healing process [83].It is also an antioxidant and suppressor of proinflammatory processes.Individuals with POTS have been 
shown to be deficient in B12 and B1. B12deficiency was proven to be significantly lower in children with POTS and B12supplements may reduce orthostatic symptoms in this population [84]. Vitamin B1 (thiamine), is a water-soluble vitamin that is integral to energymetabolism. Thiamine supplement in individuals with experiencing dysautonomiacan help promote cell growth, function, and development [10].

\section{Non-oral Nutrition and Hydration Support}

In some instances, despite optimized medicaltherapy, patients with primary dysautonomia or JHS/EDS-HT are unable to meettheir nutrition and hydration needs orally. Individuals with poor nutritionstatus may require intravenous hydration, enteral nutrition or even parenteralnutrition support. In a retrospective cohort study of 332 subjects at atertiary care hospital, patients with POTS were followed for 7 years [49••]. In the cohort, a subset of 32 patients required nutrition support, of which 66\% required intravenous fluids, $59 \%$ required enteral nutrition, and $28 \%$ required parenteral nutrition. Six of the 32 patients required all three forms of nutrition support throughout the study period. Severe GI symptoms, such asnausea and vomiting, diarrhea, constipation and abdominal pain, were more prevalent in patients receiving nutrition support and GI transit studies were more likely to indicate delayed gastric emptying, indicating that GIdysmotility is a significant factor in need for nutrition support.

\section{Dietary/Nutritional Supplements}

\section{Osteoarticular Joint Pain}

Individuals with JHS/EDS-HT commonlyexperience joint symptoms that result in functional impairment, often requiringanalgesic use and corrective surgery [85].Musculoskeletal pain is derived from acute, recurrent, or chronic inflammationof soft tissues leading to bursitis, synovitis, fasciitis, or tendinitis $[42,86]$. Castori et al. demonstrated that the prevalence of arthralgias and back pain inEDS individuals increased from approximately $30 \%$ in children to $>180 \%$ inadults over 40 years old [87]. The frequency and severity of MSK pain is dependent ongeneral lifestyle, physical activity, trauma/surgery, and co-morbidities [88].The natural history of JHS/EDS begins with sprains, dislocations, growing painwhich progresses to recurrent arthralgias, back pain, radiographicosteoarthritis, and spondylosis. In the third to fourth decade of life, chronicarthralgias, back pain, tendon/ ligament degenerations, and widespread rigidityis common. In early stage, pain is commonly localized at small to large jointsand in sensed by nociceptors. With recurrent and progressive injury,individuals with JHS become unable to localize their pain. In advanced forms ofJHS/EDS-HT, analgesic medication alone is insufficient to manage pain.

Nutritional therapies for osteoarticularjoint pain in individuals with JHS/EDS-HT are wide ranging. For joint injuryand arthritis, $1500 \mathrm{mg}$ /day of glucosamine is recommended $[89,90]$.Glucosamine is a sugar-related nutrient used by the body to synthesize complexmolecules, which are necessary to maintain, support, and repair connectivetissue and joints. Glucosamine or chondroitin have demonstrated reduction injoint space narrowing [89-91], Although not yet studied in JHS/EDS-HT individuals, chondroitin sulfate $(1200 \mathrm{mg} /$ day $)$ and manganese ascorbate $(228 \mathrm{mg} /$ day $)$ may reduce degenerative joint disease of knee or low back.

\section{Musculoskeletal and Neuropathic Pain}

Musculoskeletal pain is common and presentwithin the first decade with exertional or post-exertional myalgia/cramps andmild hypotonia in JHS/EDS-HT. In the second to third decade of life, recurrentmyalgias and focal muscle hyperalgesia may progress to chronic myalgias,fibromyalgia, and muscle weakness [88].Neuropathic pain can present as peripheral paresthesia, allodynia, generalizedmuscle hyperalgesia (including fibromyalgia), and dysesthesias.

For general muscle weakness and fibromyalgia, a supplement of $250 \mathrm{mg} / \mathrm{day}$ of carnitine and $100 \mathrm{mg} /$ day coenzyme Q10 (CoQ10) can improve symptoms [92, 93]. Carnitine is a natural compound that is an essential cofactorin fatty acid metabolism. CoQ10 is a cofactor for production of adenosinetriphosphate (ATP), an integral compound providing energy to cells such asmuscles. In a meta-analysis of 12 studies with 75 subjects, CoQ10 supplementsignificantly reduced statin-associated muscle weakness, cramp, fatigue, andpain [94]. For general inflammation, y-linolenic acid at $240 \mathrm{mg} /$ dayis recommended [88]. Y-linolenic acid is an essential fatty in cell membranesand a precursor to eicosanoids [95].Eicosanoids are compounds integral to the development and maturation of theimmune system and inflammatory response. Supplement of y-linolenic acid mayprovide the necessary precursors to repair the inflammatory and gut microbiomedysfunction.

\section{Fatigue}

Fatigue is common in patients withJHS/EDS-HT. It may present in the first decade of life and progress to poorsleep and post-exertional dyspnea [88].Fatigue can progress to severe post-exertional malaise and disabling morningfatigue. Supplements such as CoQ10, magnesium, nicotinamide adeninedinucleotide (NADH), and alpha-lipoic acid may ameliorate fatigue [96].A meta-analysis demonstrated improvement in fatigue with CoQ10 supplementationamong heart failure, multiple sclerosis, fibromyalgia, and healthy 
individuals [97].In subjects with chronic fatigue syndrome, NADH taken in combination with CoQ10has also been proven to improve fatigue [92].Magnesium levels have been shown to be lower in individuals with chronicfatigue syndrome compared to controls [98]. Furthermore, Cox et al. demonstrated in a randomized, double-blind study thatintramuscular magnesium sulphate weekly for 6 weeks resultedin less pain, improved emotional state, and overall higher energy levelscompared to placebo.

\section{Conclusion}

Dysautonomia and JHS/EDS-HT are independent but often overlapping conditions that are increasingly recognized clinically for the multisystem complexity in their presentation and symptoms. Among the range of ailments, gastrointestinal, orthostatic, osteoarticular, musculoskeletal pain, and fatigue are the most prevalent and debilitating. While there are pharmacologic therapies to address specific symptoms, nutritional management remains a cornerstone of optimizing this patient population's overall nutritional status and quality of life (Table 1). GI symptoms such as diarrhea and constipation can be reduced with increasing soluble fiber, food rich in pre and probiotics, FODMAP, or gluten-free diet. Furthermore, these modifications will promote normobiosis of the gut resulting in improved absorption and reducing leaky intestinal barrier. Orthostatic hypotension can be ameliorated with salt (6-10 g per day) and drinking (1.5-3L) fluids per day. Supplements such as glucosamine, carnitine, CoQ10 can reduce systemic symptoms of osteoarticular inflammation, musculoskeletal pain, and severe fatigue, respectively. These recommendations may be extrapolated from studies in populations afflicted by similar symptoms as those with dysautonomia, and further investigations are required to elucidate the pathophysiology of symptoms and specific benefits of nutritional support in individuals with dysautonomia and hypermobility syndrome.

Data Availability Data derived from public domain resources.

\section{Compliance with Ethical Standards}

Conflict of Interest None.

Human and Animal Rights and Informed Consent. This article does not contain any studies with human or animal subjects performed by any of the authors.

Ethics approval This literature review has not been submitted to more than one journal for consideration. To the best of authors' knowledge, all data have been cited by the original publisher to maintain integrity of scientific discovery. We will correct any fundamental errors identified in this article.
Consent to participate. All authors whose names appear on the submission made substantial contributions to the submitted manuscript.

Consent for publication. All authors whose names appear on the submission approved the version of the manuscript to be published and agree to be accountable for all aspects of the work in ensuring questions related to accuracy or integrity of any part of the work are appropriately investigated and resolved.

\section{References}

Papers of particular interest, published recently, have been highlighted as:

$\bullet$ Of major importance

1. Beighton P, Paepe AD, Steinmann B, Tsipouras P, Wenstrup RJ. Ehlers-Danlos syndromes: Revised nosology, Villefranche, 1997. Am J Med Genet. 1998;77(1):31-7. https://doi.org/10. 1002/(SICI) 1096-8628(19980428)77:1\%3c31::AID-AJMG8\% 3e3.0.CO;2-O.

2. Gazit Y, Nahir AM, Grahame R, Jacob G. Dysautonomia in the joint hypermobility syndrome. Am J Med. Jul. 2003;115(1):3340. https://doi.org/10.1016/s0002-9343(03)00235-3.

3. Simmonds JV, Keer RJ. Hypermobility and the hypermobility syndrome. Man Ther. Nov. 2007;12(4):298-309. https://doi.org/ 10.1016/j.math.2007.05.001.

4. Axelrod FB. Familial dysautonomia. Muscle Nerve. 2004;29(3):352-63. https://doi.org/10.1002/mus.10499.

5. Eshak N, et al. Dysautonomia: an Overlooked neurological manifestation in a critically ill COVID-19 patient. Am J Med Sci. Oct. 2020;360(4):427-9. https://doi.org/10.1016/j.amjms.2020. 07.022 .

6. Becker K, Görlach I, Frieling T, Häussinger D. Characterization and natural course of cardiac autonomic nervous dysfunction in HIV-infected patients. AIDS. May 1997;11(6):751-7.

7. Pearson J, Axelrod F, Dancis J. Current concepts of dysautonomia: neuropathological defects*. Ann N Y Acad Sci. 1974;228(1):288-300. https://doi.org/10.1111/j.1749-6632. 1974.tb20517.x.

8. Shohat M, Weisz Hubshman M. Familial dysautonomia, in GeneReviews ${ }^{\circledR}$, M. P. Adam, H. H. Ardinger, R. A. Pagon, S. E. Wallace, L. J. Bean, G. Mirzaa, and A. Amemiya, Eds. Seattle (WA): University of Washington, Seattle, 1993.

9. DiBaise JK, Lunsford TN, Harris LA. The POTS (Postural Tachycardia Syndrome) epidemic: hydration and nutrition issues, Pract. Gastroenterol. 2019; p. 10.

10. Blitshteyn S. Vitamin B1 deficiency in patients with postural tachycardia syndrome (POTS). Neurol Res. Aug. 2017;39(8):685-8. https://doi.org/10.1080/01616412.2017. 1331895 .

11. DiBaise JK, Harris LA, Goodman B. Postural Tachycardia Syndrome (POTS) and the GI tract: a primer for the gastroenterologist. Off J Am Coll Gastroenterol ACG. Oct. 2018;113(10):145867. https://doi.org/10.1038/s41395-018-0215-4.

12. Mandel D, Askari AD, Malemud CJ, Kaso A. Joint Hypermobility Syndrome and Postural Orthostatic Tachycardia Syndrome (HyPOTS), Biomed. Res. Clin. Pract. 2017;2(2). https://doi.org/ 10.15761/BRCP.1000132.

13. Baguley IJ, Slewa-Younan S, Heriseanu RE, Nott MT, Mudaliar Y, Nayyar V. The incidence of dysautonomia and its relationship with autonomic arousal following traumatic brain injury. 
Brain Inj. Oct. 2007;21(11):1175-81. https://doi.org/10.1080/ 02699050701687375.

14. Goldstein DS, Robertson D, Esler M, Straus SE, Eisenhofer G. Dysautonomias: clinical disorders of the autonomic nervous system. Ann Intern Med. Nov. 2002;137(9):753-63. https://doi.org/ 10.7326/0003-4819-137-9-200211050-00011.

15. Yukawa S, Tahara K, Shoji A, Hayashi H, Tsuboi N. Acute pandysautonomia as well as central nervous system involvement and peripheral neuropathies in a patient with systemic lupus erythematosus. Mod Rheumatol. Oct. 2008;18(5):516-21. https://doi. org/10.3109/s10165-008-0087-3.

16. Su XW, Palka SV, Rao RR, Chen FS, Brackney CR, Cambi F. SARS-CoV-2-associated Guillain-Barré syndrome with dysautonomia. Muscle Nerve. Jun. 2020. https://doi.org/10.1002/mus. 26988.

17. Sendur OF, Odabasi BB, Turan Y. An overlooked diagnosis in rheumatology: benign joint hypermobility syndrome. J Musculoskelet Pain. Aug. 2010;18(3):277-87. https://doi.org/10.3109/ 10582452.2010.501303.

18. Bohora S. joint hypermobility syndrome and dysautonomia: expanding spectrum of disease presentation and manifestation. Indian Pacing Electrophysiol J. Apr. 2010;10(4):158-61.

19. Malfait F, et al. The 2017 international classification of the Ehlers-Danlos syndromes, Am. J. Med. Genet. C Semin. Med. Genet. Mar. 2017;175(1):8-26. https://doi.org/10.1002/ajmg.c. 31552.

20. Grahame R. Joint hypermobility syndrome pain. Curr Pain Headache Rep. Dec. 2009;13(6):427. https://doi.org/10.1007/ s11916-009-0070-5.

21. Bridges AJ, Smith E, Reid J. Joint hypermobility in adults referred to rheumatology clinics., Ann. Rheum. Dis. Jun. 1992;51(6)793-796.

22. Schondorf R, Low PA. Idiopathic postural orthostatic tachycardia syndrome: an attenuated form of acute pandysautonomia? Neurology. Jan. 1993;43(1):132-7. https://doi.org/10.1212/wnl. 43.1_part_1.132.

23. Sheldon RS, et al. 2015 heart rhythm society expert consensus statement on the diagnosis and treatment of postural tachycardia syndrome, inappropriate sinus tachycardia, and vasovagal syncope. Heart Rhythm. Jun. 2015;12(6):e41-63. https://doi.org/10. 1016/j.hrthm.2015.03.029.

24. Freeman R, et al. Consensus statement on the definition of orthostatic hypotension, neurally mediated syncope and the postural tachycardia syndrome. Clin Auton Res Off J Clin Auton Res Soc. Apr. 2011;21(2):69-72. https://doi.org/10.1007/ s10286-011-0119-5.

25. Raj SR, Stiles LE. Special issue for the silver anniversary of Postural Tachycardia Syndrome. Auton Neurosci Basic Clin. Dec. 2018;215:1-2. https://doi.org/10.1016/j.autneu.2018.03.003.

26. Shaw $\mathrm{BH}$, et al. The face of postural tachycardia syndrome insights from a large cross-sectional online community-based survey. J Intern Med. Oct. 2019;286(4):438-48. https://doi.org/ 10.1111/joim.12895.

27. Garland EM, Celedonio JE, Raj SR. Postural tachycardia syndrome: beyond orthostatic intolerance. Curr Neurol Neurosci Rep. Jul. 2015;15(9):60. https://doi.org/10.1007/ s11910-015-0583-8.

28. Bourne K, Stiles L, Shaw B, Raj S. Socioeconomic and financial impact of postural tachycardia syndrome: data from a patient cross-sectional survey. Can J Cardiol. Oct. 2018;34(10):S194-5. https://doi.org/10.1016/j.cjca.2018.07.119.

29. Molodecky NA, et al. Increasing incidence and prevalence of the inflammatory bowel diseases with time, based on systematic review, Gastroenterology. Jan. 2012;142(1)46-54.e42; quiz e30. https://doi.org/10.1053/j.gastro.2011.10.001.
30. Simpson MMR. Benign joint hypermobility syndrome: evaluation, diagnosis, and management. J Am Osteopath Assoc. Sep. 2006;106(9):531-6. https://doi.org/10.7556/jaoa.2006.106.9. 531.

31. Remvig L, et al. Epidemiology of general joint hypermobility and basis for the proposed criteria for benign joint hypermobility syndrome: review of the literature, J Rheumatol.

32. Reuter PR, Fichthorn KR. Prevalence of generalized joint hypermobility, musculoskeletal injuries, and chronic musculoskeletal pain among American university students, PeerJ. Sep. 2019;7. https://doi.org/10.7717/peerj.7625.

33. Steinmann B, Royce PM, Superti-Furga A. the Ehlers-Danlos syndrome, in Connective Tissue and Its Heritable Disorders, John Wiley \& Sons, Ltd, 2002;431-523.

34. De Wandele I, et al. Dysautonomia and its underlying mechanisms in the hypermobility type of Ehlers-Danlos syndrome. Semin Arthritis Rheum. Aug. 2014;44(1):93-100. https://doi. org/10.1016/j.semarthrit.2013.12.006.

35. Celletti C, et al. Orthostatic intolerance and postural orthostatic tachycardia syndrome in joint hypermobility syndrome/EhlersDanlos syndrome, hypermobility type: neurovegetative dysregulation or autonomic failure?, BioMed Research International. Feb. 12, 2017. https://www.hindawi.com/journals/bmri/2017/ 9161865/ (accessed Feb. 17, 2021).

36. De Wandele I, et al. Orthostatic intolerance and fatigue in the hypermobility type of Ehlers-Danlos syndrome. Rheumatology. Aug. 2016;55(8):1412-20. https://doi.org/10.1093/rheumatology/ kew032.

37. Wallman D, Weinberg J, Hohler AD. Ehlers-Danlos syndrome and postural tachycardia syndrome: a relationship study. J Neurol Sci. May 2014;340(1-2):99-102. https://doi.org/10.1016/j.jns. 2014.03.002.

38. Kanjwal K, Saeed B, Karabin B, Kanjwal Y, Grubb BP. Comparative clinical profile of postural orthostatic tachycardia patients with and without joint hypermobility syndrome. Indian Pacing Electrophysiol J. Apr. 2010;10(4):173-8.

39. Castori M, Morlino S, Pascolini G, Blundo C, Grammatico P. "Gastrointestinal and nutritional issues in joint hypermobility syndrome/ Ehlers-Danlos syndrome, hypermobility type,” Am. J. Med. Genet. C Semin. Med. Genet. 2015;169(1):54-75. https://doi.org/10.1002/ ajmg.c.31431.

40. Castori M. Ehlers-danlos syndrome, hypermobility type: an underdiagnosed hereditary connective tissue disorder with mucocutaneous, articular, and systemic manifestations. ISRN Dermatol. 2012;2012: 751768. https://doi.org/10.5402/2012/ 751768.

41. Zarate N, et al. Unexplained gastrointestinal symptoms and joint hypermobility: is connective tissue the missing link? Neurogastroenterol Motil Off J Eur Gastrointest Motil Soc. Mar. 2010;22(3):252-e78. https://doi.org/10.1111/j.1365-2982.2009. 01421.x.

42. Fikree A, et al. A prospective evaluation of undiagnosed joint hypermobility syndrome in patients with gastrointestinal symptoms. Clin Gastroenterol Hepatol. Oct. 2014;12(10):1680-1687. e2. https://doi.org/10.1016/j.cgh.2014.01.014.

43. Zhou W, Zikos T, Neshatian L, Nguyen L. S0476 high prevalence of methane predominant small bowel bacterial overgrowth and constipation in patients with hypermobile Ehlers-Danlos syndrome. Off J Am Coll Gastroenterol ACG. Oct. 2020;115:S238. https://doi.org/10.14309/01.ajg.0000703952.17443.b0.

44. McCorry LK. Physiology of the autonomic nervous system, Am. J. Pharm. Educ. Aug. 2007;71(4). Accessed: Feb. 02, 2021. [Online]. Available: https://www.ncbi.nlm.nih.gov/pmc/articles/ PMC1959222/. 
45. Tougas $\mathrm{G}$. The autonomic nervous system in functional bowel disorders, Gut. Dec. 2000;47(90004):78iv-7880. https://doi.org/ 10.1136/gut.47.suppl_4.iv78.

46. Rodgers KR, Gui J, Dinulos MBP, Chou RC. Ehlers-Danlos syndrome hypermobility type is associated with rheumatic diseases, Sci. Rep. Jan. 2017;7. https://doi.org/10.1038/srep39636.

47. Tomasello G, et al. Nutrition, oxidative stress and intestinal dysbiosis: Influence of diet on gut microbiota in inflammatory bowel diseases. Biomed Pap. Dec. 2016;160(4):461-6. https:// doi.org/10.5507/bp.2016.052.

48.• Ganesh R, Bonnes SLR, DiBaise JK. Postural tachycardia syndrome: nutrition implications. Nutr Clin Pract. 2020;35(5):81825. https://doi.org/10.1002/ncp.10564. Most current nutritional implication of inidividuals with POTS.

49.•• Tseng AS, et al. Factors associated with use of nonoral nutrition and hydration support in adult patients with postural tachycardia syndrome. J Parenter Enter Nutr. A. 2019;43(6):734-41. https:// doi.org/10.1002/jpen.1493. Recognizing that due to poor oral tolerance,individuals with POTS may require non-oral nutritional support.

50. Venegas-Borsellino C, Kwon M. Impact of soluble fiber in the microbiome and outcomes in critically ill patients. Curr Nutr Rep. Dec. 2019;8(4):347-55. https://doi.org/10.1007/ s13668-019-00299-9.

51. Halmos EP. Role of FODMAP content in enteral nutritionassociated diarrhea. J Gastroenterol Hepatol. 2013;28(S4):258. https://doi.org/10.1111/jgh.12272.

52. Pinto-Sanchez MI, et al. Gluten-free diet reduces symptoms, particularly diarrhea, in patients with irritable bowel syndrome and antigliadin IgG. Clin Gastroenterol Hepatol. Aug. 2020. https:// doi.org/10.1016/j.cgh.2020.08.040.

53. Guandalini S. Probiotics for prevention and treatment of diarrhea., J. Clin. Gastroenterol. 2011;45(Suppl. 3):S149S153. https://doi.org/10.1097/MCG.0b013e3182257e98.

54. Yang J, Wang H-P, Zhou L, Xu C-F. Effect of dietary fiber on constipation: a meta analysis. World J Gastroenterol WJG. Dec. 2012;18(48):7378-83. https://doi.org/10.3748/wjg.v18.i48.7378.

55. Martinez-Guryn K, Leone V, Chang EB. Regional diversity of the gastrointestinal microbiome. Cell Host Microbe. Sep. 2019;26(3):314-24. https://doi.org/10.1016/j.chom.2019.08.011.

56. Kim CH. Immune regulation by microbiome metabolites. Immunology. Jun. 2018;154(2):220-9. https://doi.org/10.1111/imm. 12930.

57. Chang EB, Martinez-Guryn K. Small intestinal microbiota: the neglected stepchild needed for fat digestion and absorption. Gut Microbes. Mar. 2019;10(2):235-40. https://doi.org/10.1080/ 19490976.2018.1502539.

58. Kau AL, Ahern PP, Griffin NW, Goodman AL, Gordon JI. Human nutrition, the gut microbiome and the immune system. Nature. Jun. 2011;474(7351):327-36. https://doi.org/10.1038/ nature 10213.

59.•• Kumar R, Sood U, Gupta V, Singh M, Scaria J, Lal R. Recent advancements in the development of modern probiotics for restoring human gut microbiome dysbiosis. Indian J Microbiol. Mar. 2020;60(1):12-25. https://doi.org/10.1007/s12088-01900808-y. Importance of specific foods with probioticsthat can help reestablish human gut microbiome.

60. Shadnoush M, et al. probiotic yogurt affects pro- and anti-inflammatory factors in patients with inflammatory bowel disease. Iran J Pharm Res IJPR. 2013;12(4):929-36.

61. Iqbal M, Qadir M, Mallhi T, Janbaz K, Khan Y, Ahmad B. Probiotics and their beneficial effects against various diseases. Pak J Pharm Sci. Mar. 2014;27:405-15.
62. Manning TS, Gibson GR. Prebiotics. Best Pract Res Clin Gastroenterol. Apr. 2004;18(2):287-98. https://doi.org/10.1016/j. bpg.2003.10.008.

63. Miller MJ, Angeles FM, Reuter BK, Bobrowski P, Sandoval M. Dietary antioxidants protect gut epithelial cells from oxidant-induced apoptosis. BMC Complement Altern Med. Dec. 2001;1(1):11. https://doi.org/10.1186/1472-6882-1-11.

64. Bjørklund $\mathrm{G}$, Chirumbolo $\mathrm{S}$. Role of oxidative stress and antioxidants in daily nutrition and human health. Nutrition. Jan. 2017;33:311-21. https://doi.org/10.1016/j.nut.2016.07.018.

65. Bielinska K, et al. High salt intake increases plasma trimethylamine N-oxide (TMAO) concentration and produces gut dysbiosis in rats. Nutrition. Oct. 2018;54:33-9. https://doi.org/10.1016/j.nut.2018.03. 004.

66. Suez J, et al. Artificial sweeteners induce glucose intolerance by altering the gut microbiota. Nature. Oct. 2014;514(7521):181-6. https://doi.org/10.1038/nature13793.

67. Emamat H, Ghalandari H, Tangestani H, Abdollahi A, Hekmatdoost A. Artificial sweeteners are related to non-alcoholic fatty liver disease: microbiota dysbiosis as a novel potential mechanism. EXCLI J. May 2020;19:620-6. https://doi.org/10. 17179/excli2020-1226.

68. Rodriguez-Palacios A, et al. The artificial sweetener splenda promotes gut proteobacteria, dysbiosis, and myeloperoxidase reactivity in Crohn's disease-like ileitis. Inflamm Bowel Dis. Apr. 2018;24(5):1005-20. https://doi.org/10.1093/ibd/izy060.

$69 . \bullet$ Camilleri M. Leaky gut: mechanisms, measurement and clinical implications in humans, Gut. Aug. 2019;68(8):15161526. https://doi.org/10.1136/gutjnl-2019-318427. Demonstrating the importance of maintenance of the gastrointestinal barrier and disease manifestations.

70. Leclercq S, et al. Intestinal permeability, gut-bacterial dysbiosis, and behavioral markers of alcohol-dependence severity. Proc Natl Acad Sci. Oct. 2014;111(42):E4485-93. https://doi. org/10.1073/pnas.1415174111.

71. Engen PA, Green SJ, Voigt RM, Forsyth CB, Keshavarzian A. The gastrointestinal microbiome. Alcohol Res Curr Rev. 2015;37(2):223-36.

72. Mathias CJ, Young TM. Water drinking in the management of orthostatic intolerance due to orthostatic hypotension, vasovagal syncope and the postural tachycardia syndrome. Eur J Neurol. 2004;11(9):613-9. https://doi.org/10.1111/j.14681331.2004.00840.x.

73. Shannon JR, et al. Water drinking as a treatment for orthostatic syndromes. Am J Med. Apr. 2002;112(5):355-60. https://doi. org/10.1016/S0002-9343(02)01025-2.

74. Puvi-Rajasingham S, Mathias CJ. Effect of meal size on postprandial blood pressure and on postural hypotension in primary autonomic failure. Clin Auton Res. Apr. 1996;6(2):1114. https://doi.org/10.1007/BF02291232.

75.•• Shen W-K, et al. 2017 ACC/AHA/HRS guideline for the evaluation and management of patients with syncope: a report of the American College of Cardiology/American Heart Association Task Force on Clinical Practice Guidelines and the Heart Rhythm Society. Heart Rhythm. Aug. 2017;14(8):e155-217. https://doi.org/10.1016/j.hrthm.2017.03.004. Fluidintake is a topic of debate in orthostatic hypotension but the guideline hereis supporting of fluid intake.

76. Lanier JB, Mote MB, Clay EC. Evaluation and management of orthostatic hypotension. 2011;84(5):10.

77. Loughlin EA, et al. Increased salt intake for orthostatic intolerance syndromes: a systematic review and meta-analysis. Am J Med. Dec. 2020;133(12):1471-1478.e4. https://doi.org/10. 1016/j.amjmed.2020.05.028. 
78. Low PA, Singer W. Update on management of neurogenic orthostatic hypotension. Lancet Neurol. May 2008;7(5):451-8. https:// doi.org/10.1016/S1474-4422(08)70088-7.

79. Figueroa JJ, Basford JR, Low PA. preventing and treating orthostatic hypotension: as easy as A, B, C. Cleve Clin J Med. May 2010;77(5):298-306. https://doi.org/10.3949/ccjm.77a.09118.

80. Busch A, et al. Vascular type Ehlers-Danlos syndrome is associated with platelet dysfunction and low vitamin D serum concentration. Orphanet J Rare Dis. Aug. 2016;11(1):111. https://doi. org/10.1186/s13023-016-0491-2.

81. Holick MF, Hossein-Nezhad A, Tabatabaei F. Multiple fractures in infants who have Ehlers-Danlos/hypermobility syndrome and or vitamin D deficiency: a case series of 72 infants whose parents were accused of child abuse and neglect. Dermatoendocrinol. Jan. 2017;9(1): e1279768. https://doi.org/10.1080/19381980. 2017.1279768.

82. Mantle D, Wilkins RM, Preedy V. A novel therapeutic strategy for Ehlers-Danlos syndrome based on nutritional supplements. Med Hypotheses. Jan. 2005;64(2):279-83. https://doi.org/10. 1016/j.mehy.2004.07.023.

83. Mohammed BM, et al. Vitamin C promotes wound healing through novel pleiotropic mechanisms. Int Wound J. 2016;13(4):572-84. https://doi.org/10.1111/iwj.12484.

84. Öner T, Guven B, Tavli V, Mese T, Yılmazer MM, Demirpence S. Postural orthostatic tachycardia syndrome (POTS) and vitamin B12 deficiency in adolescents. Pediatrics. Jan. 2014;133(1):e138-42. https://doi.org/10.1542/peds.2012-3427.

85. Sacheti A, Szemere J, Bernstein B, Tafas T, Schechter N, Tsipouras P. Chronic pain is a manifestation of the Ehlers-Danlos syndrome. J Pain Symptom Manage. Aug. 1997;14(2):88-93. https://doi.org/10.1016/s0885-3924(97)00007-9.

86. Ross J, Grahame R. Easily mised? Joint hypermobility syndrome, BMJ. Jan. 2011;342: c7167. https://doi.org/10.1136/ bmj.c7167.

87. Castori M. Pain in Ehlers-Danlos syndromes: manifestations, therapeutic strategies and future perspectives. Expert Opin Orphan Drugs. Nov. 2016;4(11):1145-58. https://doi.org/10. 1080/21678707.2016.1238302.

88. Castori M, Celletti C, Camerota F. Ehlers-Danlos syndrome hypermobility type: a possible unifying concept for various functional somatic syndromes. Rheumatol Int. Mar. 2013;33(3):81921. https://doi.org/10.1007/s00296-011-2275-2.

89. Richy F, Bruyere O, Ethgen O, Cucherat M, Henrotin Y, Reginster J-Y. Structural and symptomatic efficacy of glucosamine and chondroitin in knee osteoarthritis: a comprehensive meta-analysis. Arch Intern Med. Jul. 2003;163(13):1514-22. https://doi.org/10.1001/ archinte.163.13.1514
90. Reginster JY, et al. Long-term effects of glucosamine sulphate on osteoarthritis progression: a randomised, placebo-controlled clinical trial. The Lancet. Jan. 2001;357(9252):251-6. https:// doi.org/10.1016/S0140-6736(00)03610-2.

91. Philippi AF, Leffler CT, Leffler SG, Mosure JC, Kim PD. Glucosamine, chondroitin, and manganese ascorbate for degenerative joint disease of the knee or low back: a randomized, double-blind, placebo-controlled pilot study. Mil Med. Feb. 1999;164(2):85-91. https://doi.org/10.1093/milmed/164.2.85.

92. Nicolson GL, Settineri R, Ellithorpe R. Lipid replacement therapy with a glycophospholipid formulation with NADH and CoQ10 significantly reduces fatigue in intractable chronic fatiguing illnesses and chronic lyme disease patients. May. 2012;2012. https://doi.org/10.4236/ijcm.2012.33034.

93. Borum PR. Carnitine in parenteral nutrition. Gastroenterology. Nov. 2009;137(5):S129-34. https://doi.org/10.1053/j.gastro. 2009.08.016.

94. Voermans NC, Knoop H, van de Kamp N, Hamel BC, Bleijenberg G, van Engelen BG. Fatigue is a frequent and clinically relevant problem in Ehlers-Danlos syndrome. Semin Arthritis Rheum. Dec. 2010;40(3):267-74. https://doi.org/10.1016/j.semarthrit. 2009.08.003.

95. Zurier B. Essential fatty acids and inflammation., Ann. Rheum. Dis. Nov. 1991;50(11):745-746.

96. Hakim A, Wandele ID, O'Callaghan C, Pocinki A, Rowe P. Chronic fatigue in Ehlers-Danlos syndrome-hypermobile type, Am. J. Med. Genet. C Semin. Med. Genet. 2017;175(1):175180. https://doi.org/10.1002/ajmg.c.31542.

97. Mehrabani S, Askari G, Miraghajani M, Tavakoly R, Arab A. Effect of coenzyme Q10 supplementation on fatigue: a systematic review of interventional studies. Complement Ther Med. Apr. 2019;43:181-7. https://doi.org/10.1016/j.ctim.2019.01.022.

98. Cox IM, Campbell MJ, Dowson D. Red blood cell magnesium and chronic fatigue syndrome. The Lancet. Mar. 1991;337(8744):757-60. https://doi.org/10.1016/0140-6736(91) 91371-Z

99. Singh A, Zapata RC, Pezeshki A, Reidelberger RD, Chelikani PK. Inulin fiber dose-dependently modulates energy balance, glucose tolerance, gut microbiota, hormones and diet preference in high-fat-fed male rats. J Nutr Biochem. Sep. 2018;59:142-52. https://doi.org/10.1016/j.jnutbio.2018.05.017.

Publisher's Note Springer Nature remains neutral with regard to jurisdictional claims in published maps and institutional affiliations. 